Journal of Research in Interprofessional

Practice and

Education

Vol. 1.3

December, 2010

\section{Assessing Interprofessional Learning during a Student Placement in an Interprofessional Rehabilitation University Clinic in Primary Healthcare in a Canadian Francophone Minority Context}

\author{
Paulette Guitard, PhD, OT Reg. (Ont); Claire-Jehanne Dubouloz, PhD, \\ OT Reg. (Ont); Jacinthe Savard, PhD, OT Reg. (Ont); Lynn Metthé, MScS, \\ Reg. CASLPO; Anne Brasset-Latulippe, MSc, OT reg (Ont)
}

\begin{abstract}
Background: Interprofessional collaboration is deemed the key to quality patient care and the future for healthcare delivery models. Such a complex competency needs to be learned; as such, interprofessional education should be a key component of health professional programs. An Interprofessional Rehabilitation University Clinic was created to promote interprofessional education at the pre-licensure level. However, few resources are currently available to assess interprofessional learning; no tool (English or French) that specifically assesses interprofessional learning could be identified.
\end{abstract}

Methods and Findings: A self-administered questionnaire was developed to assess interprofessional learning during a clinical placement. Using a single-group posttest-only design, this descriptive pilot project reports the results obtained with this tool for the first 15 students on placement at the Clinic. Preliminary findings suggest this tool helped demonstrate that, during placements in an interprofessional clinic, students developed some understanding of their own profession as well as of other professions. Responses showed that participants believe that interprofessional interventions are more efficient, save time, and facilitate sharing of information leading to a better comprehension of the clients' situations. The tool suggests that students feel that an interprofessional educational experience is beneficial for clients and for themselves.

Conclusions: Assessing interprofessional learning is challenging. Although the tool developed during this project is most promising, further research is warranted to increase its usefulness in assessing interprofessional learning.

Keywords: Interprofessional education; Fieldwork; Interprofessional learning assessment

\section{Introduction}

Interprofessional collaboration is considered the key to quality patient care and, consequently, the future direction of healthcare delivery models $[1,2]$. Studies have shown that many barriers need to be overcome for health and social care professionals to collaborate [3,4]. A possible explanation for this lack of collaboration may be a poor understanding of other professions. Interprofessional collaboration is a complex competency that needs to be learned and developed throughout the learning process [1]. Interprofessional education should be a key component of health educational programs to ensure that students from different professions learn together 
232

Assessing Interprofessional Clinical Learning

Guitard, Dubouloz, Savard, Metthé, \& Brasset-Latulippe

Journal of Research in Interprofessional Practice and Education

Vol. 1.3

December, 2010 from and about one another to facilitate collaborative practice [5, 6]. Most pre-qualification courses, and the majority of healthcare professionals, have little or no formal academic experience and/or clinical training or education with or about other professions [1].

Interprofessional education (IPE) experiences during clinical placements have been explored in a community health centre for an HIV population [7], an interprofessional university-conducted clinic [8], an interprofessional training ward [9], an acute hospital training centre [10], and in a new interprofessional field placement initiative at the pre-licensure level focused on the collaborative practice of health promotion [11]. Results from these studies suggest that interprofessional placements help students gain a better understanding of their own profession as well as of other professions [7,8,9,11] and a greater understanding of clients' problems [8].

In 2006, an Interprofessional Rehabilitation University Clinic in Primary Health Care (IRUC-PHC) was created to promote interprofessional education at the prelicensure level. This unique and innovative clinical training centre employs an interprofessional approach to healthcare professional education, while providing highly focused client services to the francophone minority population of the region. The IRUC-PHC offers interprofessional education placements to students from 8 different professions: audiology, human kinetics, medicine, nursing, occupational therapy, physical therapy, social work, and speech-language pathology. This provides a unique experience for students to work together to gain knowledge and understanding of other professions, and to strengthen their understanding of their own profession. The IRUC-PHC uses the Model of Disability Creation Process to understand health and disability [12] and to teach students to view health as an outcome of social participation. Embracing the Collaborative Patient-Centred Practice Model (CPCP) $[2,13,14]$, the IRUC-PHC requires a high degree of collaboration between team members, promotes working toward a common goal for the client, and employs a common decision-making process based on the integration of each professional's knowledge and expertise. The implementation and application of interprofessional education at the IRUC-PHC is described in a previous article [15]. Finally, learning processes are based on theories of adult education such as the adult learning theory [16] and the experiential learning theory [17].

Students complete a clinical placement at the IRUC-PHC as part of their programs' regular placement rotations, under the supervision of a team of five regulated educator-clinicians (audiologist, nurse, occupational therapist, physiotherapist, and speech-language pathologist). Three different types of clinical placements are offered: observation placements, rehabilitation placements, and health promotion placements. The length of placements varies according to each profession and the type of placement; they range from 1-2 days of observation to 60-day full-time placements. Students completing an interprofessional placement must meet their program's specific evaluation requirements. In addition, by the end of their placements, they must meet the three following interprofessional learning objectives:

- explain to other professionals the roles and responsibilities of each profession involved in providing care at the IRUC-PHC (cognitive 
Assessing Interprofessional Clinical Learning

Guitard, Dubouloz, Savard, Metthé, \& Brasset-Latulippe

Journal of Research in Interprofessional Practice and Education

Vol. 1.3

December, 2010

\section{Journal of Research in Interprofessional Practice and Education}

domain, comprehension level according to Blooms' taxonomy $[18,19])$

- learn to work with francophone clients, other students, educator-clinicians in order to assess, plan, provide, and reassess care (cognitive domain, application level according to Blooms' taxonomy $[18,19])$

- adhere to the four interactional determinants of collaboration during clinical interventions (collaboration, respect, communication, and trust) [20] (affective domain [21])

How can interprofessional learning be assessed? Interprofessional education experiences are fairly recent. Consequently, very little research pertaining to interprofessional learning exists. As such, few resources are available to assess interprofessional learning, particularly in French (primary language of the IRUC-PHC). In the studies pertaining to interprofessional learning previously mentioned, learning was either not formally assessed or assessed with pre- and post- in-house questionnaires. A review of the literature reveals that some standardized instruments have been developed to assess IPE experiences. According to Mattick \& Bligh [22], the Readiness for Interprofessional Learning Scale (RIPLS) [23], is the standardized tool most frequently used in IPE. This tool measures the attitude of students toward interprofessionalism. Similar tools have been proposed: the Interdisciplinary Education Perception Scale [24], the Interprofessional Attitudes Questionnaire [25], the Attitudes to Health Professionals Questionnaire [26], and the Interdisciplinary Education Perception Scale [27]. These tools pertain to perception and attitudes toward interprofessionalism. However, attitudes toward interprofessional learning and collaboration may not be the best indicator of student interprofessional learning. In a study of 11 different healthcare programs, receptivity to interprofessional learning was generally high among freshman [28]. Others also found little or no change in attitudes after interprofessional learning activities [15,29]. Students choosing such placements may already be favorable to interprofessional collaboration. Thus it may be difficult to capture a difference in attitudes between the beginning and the end of the placement.

The Team Orientation and Behaviour Inventory and The Group Growth Evaluation Form have also been used [24]. These tools assess team functioning. Another similar assessment was also identified: The Team Assessment [30]. Another group developed a model to help diagnose team collaboration [31]. Finally, the Generic Role Perception Questionnaire [32] was used to assess undergraduate students' perceptions of the role of a range of professions. In summary, tools exist to assess attitudes, perceptions, and behaviours toward interprofessionalism, but no tool could be identified that specifically evaluates interprofessional learning.

Confronted with this paucity of tools, both in English and in French, the team at the Clinic developed the Réflexion personnelle sur l'apprentissage interprofessionnel lors d'un stage en réadaptation (Personal Reflective Tool) to assess knowledge, skills, attitudes, and behaviours acquired during an interprofessional placement. Based on learning theories $[16,17]$, it was felt that learning could differ among students as they entered interprofessional experiences with different backgrounds, having had differ- 
Assessing Interprofessional Clinical Learning

Guitard, Dubouloz, Savard, Metthé, \& Brasset-Latulippe

Journal of Research in Interprofessional Practice and Education

Vol. 1.3 December, 2010 ent previous clinical experiences. Furthermore, they may not encounter the same experiences during their interprofessional placement at the IRUC-PHC. Consequently, given the unique learning context of each student, we felt that a written, semi-structured questionnaire was the best means to capture how the students perceived and comprehended their experiences at the IRUC-PHC. We wanted an instrument that would help tease out what and how students learned in order to understand the specific events that directed their learning experiences. This new tool was added to the other evaluation documentation already required by each specific educational program and was meant to be part of the regular placement evaluation that all students completed during a placement at the clinic. This Personal Reflective Tool focused on the interprofessional learning experiences encountered by students to help identify the following: 1) the cognitive level at which learning occurs, 2) the students' perceptions regarding the importance of the interactional determinants of collaboration, 3) the students' knowledge of the roles and responsibilities of the other healthcare professionals, and 4) the impact of an interprofessional practice experience on students. The tool consisted of six open-ended written questions designed to be completed at the end of each interprofessional placement (Appendix 1).

A pilot project was designed to explore the usefulness of the Personal Reflective Tool in assessing the learning fostered through an interprofessional placement as part of the IRUC-PHC program evaluation. The University's Ethics Board reviewed the project and concluded that, as this study was part of a program evaluation, no ethical approval was required.

In this article, we describe the methodology and the findings of the pilot project. Next, we discuss the findings and present recommendations to improve the tool to better assess interprofessional learning.

\section{Methods and findings}

The objective of this project was to determine if the Personal Reflective Tool developed could help assess learning during an interprofessional placement using a singlegroup post-test-only design. As the tool draws on unique student learning experiences, a generic qualitative approach was used [33] to analyze the students' responses to the Personal Reflective Tool. Generic qualitative studies are among the most frequent forms of qualitative research in education [34]. This generic approach "is not guided by an explicit or established set of philosophic assumptions in the form of one of the known qualitative methodologies" [33, p. 19], but it uses concepts from the theoretical framework to identify recurring patterns, categories, or factors that further delineate the theoretical frame [33]. In the present study, the purpose is to demonstrate the use of the tool to describe what students have learned during an IPE experience and how this learning occurred.

\section{Description of the sample}

During its first year of operation (2006-2007 academic year), 74 students from six different professions completed a total of 500 days of clinical placement at the IRUC-PHC. As mentioned earlier, there are several types of placements offered. It 
Assessing Interprofessional Clinical Learning

Guitard, Dubouloz, Savard, Metthé, \& Brasset-Latulippe

Journal of Research in Interprofessional Practice and Education

Vol. 1.3 December, 2010

\section{Journal of Research in Interprofessional Practice and Education}

was felt that the observation placements and the health promotion placements were too short to capture any changes in interprofessional learning. Thus, only the data from the rehabilitation placements of at least 12 days were included in this pilot study. The average placement duration was 27 days. Of the 18 students from rehabilitation sciences who went through such a placement, 15 completed the questionnaire: audiology $(N=1)$, occupational therapy $(N=6)$, physiotherapy $(N=7)$, and speech-language pathology $(N=1)$.

\section{Data collection}

The Personal Reflective Tool was completed by the students on the last day of placement. A data sheet was also completed that compiled specific information on each student (educational program, gender, level, and length of placement at the IRUCPHC). Individually, at their own pace, students were asked to complete this tool and write their answers on the questionnaire given to them. Completion of this tool took between 20 to 45 minutes. Once completed, students submitted the questionnaire to the administrative assistant who deleted any personal information that would identify the participant. Answers were transcribed by a research assistant to produce an electronic file for each participant.

\section{Data analysis}

Several strategies were used to analyze the data. Question 1 sought to determine at what level learning occurred. Each answer (quote) was analyzed according to Bloom's $[18,19]$ taxonomy in order to determine at which level (knowledge, comprehension, application, analysis, synthesis, or evaluation) learning occurred. Our research assistant analyzed each answer and identified the corresponding level of learning. This first draft was sent to all members of the research team who individually reviewed the classification. A discussion between the whole team and the research assistant followed to obtain consensus for each answer. For question 2, each answer was classified according to which interactional determinants (willingness to collaborate, trust, communication, mutual respect) was identified. The previously described process was used to achieve consensus. Finally, answers to questions $3,4,5$, and 6 were submitted to content analysis to identify emerging themes related to the impact of interprofessional placement on the students, on their perception of its impact on the clients, and on the students' disciplinary and interprofessional knowledge. The coding and categorization was done first by our research assistant, then it was validated by our senior qualitative researchers, and finally it was reviewed by the whole team in three separate meetings. Consensus was reached for each categorization.

\section{Findings}

The findings of these analyses are presented below. Quotes from participants are used to illustrate findings. To facilitate reading, quotes were translated from French to English and shortened to their simplest form without changing their meaning. 
Assessing Interprofessional Clinical Learning

Guitard, Dubouloz, Savard, Metthé, \& Brasset-Latulippe

Journal of Research in Interprofessional Practice and Education

Vol. 1.3

December, 2010

\section{Journal of Research in Interprofessional Practice and Education}

\section{Question 1. Level of knowledge}

According to the students' responses, learning occurred at the first three levels of Bloom's taxonomy [18,19]: the knowledge, comprehension, and application levels. Almost all students seemed to have learned at the first level (knowledge level) as they were able to recall some factual information from another profession.

P03: Speech-language pathology intervention: working with the muscles of the mouth, tongue, to improve speech.

One participant demonstrated learning at the second level (comprehension level), which relates to understanding the meaning, translation, interpolation, and interpretation of instructions and problems, as illustrated below.

P08: I knew that occupational therapists were doing Activities of Daily Living (ADL) assessment, but I would have never thought that they were observing individuals in the kitchen while they were ACTUALLY cooking and in the bathroom REALLY washing themselves. I did not know they were that specific!

One participant demonstrated learning at the third level (application level) as he/she was able to use a concept from another discipline in one of his/her own clinical situations.

P04: My first example is speech language pathology treatment and how this can be integrated in a physiotherapy treatment by counting the number of repetitions using different methods.

\section{Question 2. Interactional determinants of collaboration}

Responses demonstrated that, overall, participants recognized the importance of all four interactional determinants. The majority of the participants (8) gained a better understanding of the concept of willingness to collaborate; four of the 15 participants learned about the importance of communication, three learned about trust, and two learned about respect. Two students felt that communication and willingness to collaborate were equally important. The following quotes illustrate these different understandings.

P09: To put together willingness to collaborate and communication. When my supervisor was asking the other professionals if I could observe their intervention, they were very accepting.

P04: Knowing how a client reacts during a specific intervention may contribute to better focusing our own intervention. A good sharing of information while trying to understand the others' perspectives is essential to formulate an interdisciplinary model of care.

P013: "There is a real students' interest to know/understand what others are doing in the domain (of practice). The students thrust each others, which, according to me, increase feeling of self competency." 
Assessing Interprofessional Clinical Learning

Guitard, Dubouloz, Savard, Metthé, \& Brasset-Latulippe
Journal of Research in Interprofessional Practice and Education

Vol. 1.3

December, 2010

\section{Journal of Research in Interprofessional Practice and Education}

P03: When respect and understanding of the other professions are present, it is possible to create interesting interventions for the patients as well as the professionals."

\section{Question 3. Impact of IPE intervention}

Findings suggest that students believe that IPE is beneficial to clients, to professionals, and to themselves. First, students felt that interprofessional intervention benefitted clients by decreasing fatigue, increasing intervention efficacy, increasing motivation, being more time efficient, and ensuring better services. Students felt that interprofessional interventions led to increased communication between professionals, thereby leading to interventions better suited to clients' situations.

P02: A child will be less tired than if he had received 2 treatments and will understand the importance of the integration of both aspects, for example, that positioning is important to write better.

P08: Completing interprofessional assessments allowed [us] to highlight important elements that may have gone unnoticed if the assessment had been done by only one discipline.

P13: Each profession has its specialties. By having an interprofessional intervention, you can see the situation from different angles, which allows you to offer a more complete intervention.

Second, students' answers suggest that interprofessional intervention was also beneficial for the professionals involved because, as it is original, new, and facilitates better relationships between team members, it was more time efficient and motivating.

P12: In a small amount of time we were able to assess the client's needs in the bathroom, as well as for a new walker, plus assess balance and plan an exercise program!

P07: The fact that each professional is present and that they all discuss together leads to a global view of the clients and their needs.

P17: The professions complete one another well, and it is important to know what objective the other is working toward in order to pursue in the same direction.

Finally, students believed that interprofessional intervention had an impact on them as learners. When comparing a traditional (disciplinary) versus an interprofessional placement, students felt that during interprofessional placement they had better access to other professions, which increased their knowledge of another discipline to the point where they could contemplate integrating some knowledge and strategies learned from this discipline into their own interventions. They felt that the increased sharing of information helped them complete their own evaluations and gain a better understanding of the client. 
Assessing Interprofessional Clinical Learning

Guitard, Dubouloz, Savard, Metthé, \& Brasset-Latulippe

Journal of Research in Interprofessional Practice and Education

Vol. 1.3

December, 2010

\section{Journal of Research in Interprofessional Practice and Education}

P11: We have learned to use the speech binders during physio sessions with aphasic clients to facilitate the physio/patient interaction.

P04: During a joint physio-OT session, I learned that the performance of a child must not only be seen as the ability or inability to perform a physical task. It is also important to note the cognitive aspect behind the scene, namely if motor planning limits the physical ability.

\section{Question 4. Unexpected learning and insight gained}

Answers suggest that students were really surprised to learn so much about other professions. Interprofessional training allowed students to gain a deeper understanding of the roles and responsibilities of other professions, type of clients served, evaluation tools used, and methods of treatment or intervention.

P10: I didn't know that in occupational therapy they worked on selfesteem.

Not only did students gain better knowledge of other professions, they were also surprised to realize the limits of their own profession. Interprofessional training allowed students to compare the contribution of their own practice with that of other professions when considering various professional approaches to treatment.

P19: Speech-language pathologists are also involved with swallowing in conjunction with (us) physios. Swallowing problems can lead to respiratory complications such as pneumonia. Therefore, it is important to ensure that a client has good swallowing to maintain a healthy respiratory system.

Furthermore, students realized that their own intervention may be enriched by gaining a greater understanding of the clients' situations through an interprofessional approach. IPE enabled them to improve their own practice and, subsequently, the well being of the client.

P07: When each professional analyses the case and looks at the deficits, we can, together, offer a better service. The fact that each professional is present and that we discuss together, we can have a better perspective and better target the client's needs.

Students also gained better awareness of how to work in a team; effective team work was perceived as requiring respect and confidence among team members. Harmonious relationships, good communication, and mutual respect were essential ingredients to effective team work.

P11: I now have a much better understanding of the importance of communication between professionals.

Team work was perceived as very beneficial but not always easy. Students realized some challenges to interprofessional intervention. 
Assessing Interprofessional Clinical Learning

Guitard, Dubouloz, Savard, Metthé, \& Brasset-Latulippe
Journal of Research in Interprofessional Practice and Education

Vol. 1.3

December, 2010

\section{Journal of Research in Interprofessional Practice and Education}

P09: The logistics necessary to coordinate the schedules of work for all professions requires much work.

Many were surprised to see that clients may improve with the interventions from another profession and that they were still able to do certain things despite their impairments. Answers suggested that students had preconceived ideas of patients' capacities.

P08: I realized that despite sometimes severe hemiplegia, many clients can lead a fulfilling life, be very independent and functional.

In summary, answers to this question suggest that interprofessional training facilitated both the acquisition of knowledge and a certain professional awakening within students, leading them to recognize the added value of interprofessional care and the benefits of a holistic approach. Answers suggest that the "proximity to the client, in this type of practice" was also instrumental in the learning and insights gained by students.

\section{Question 5. Thinking differently}

Answers suggest that interprofessional training brought students to think differently by helping them realize the importance of the environment and the limits of their own intervention. Students realized how the environment could affect clients' function and that people will not automatically function the same way in the hospital and at home. This observation was triggered by comparing different previous clinical experiences. Students realized the importance of modifying the environment as a suitable alternative to therapy for clients who have reached a plateau.

P19: I have realized that some clients may not improve or very little and that it is important to find an alternative like modifying the environment.... After a visit with an occupational therapist, I understood the importance of assistive devices, especially during bath transfers.

Students' perspectives on a client's potential had changed. Not only did they gain a better sense of what they could offer clients, they also realized that they could work with a large range of clients with different levels of function and recovery. Interprofessional interactions were perceived as enabling clients to do more despite their incapacity.

P11: Having met with (someone who had a stroke), now I am certain that the physiotherapy treatment can help in regaining mobility in paralyzed patients! I believe that some patients can succeed in spite of their paralysis.

\section{Question 6. Modification of work habits}

Answers suggest that interprofessional practice led students to make two major changes in their own practice. First, they modified their work habits. Having more respect for other professions and a greater appreciation and understanding of the 
Assessing Interprofessional Clinical Learning

Guitard, Dubouloz, Savard, Metthé, \& Brasset-Latulippe

Journal of Research in Interprofessional Practice and Education

Vol. 1.3

December, 2010

\section{Journal of Research in Interprofessional Practice and Education}

importance of team work, students felt the need to be organized and to do things progressively to avoid accumulation and undue delays. Second, students were now trying to incorporate the strategies of other professions in their own interventions to better meet the needs of clients.

P04: I realized that I can integrate and encourage strategies taught in speech in my physio treatment.

\section{Discussion}

In this section, we compare our findings to those reported by others studies. In addition, we discuss the process used and changes to the tool required to assess IPE learning. And finally, we present the limits of the current project as well as areas for future research.

The main objective of this project was to explore the usefulness of the Personal Reflective Tool, which was developed to assess the interprofessional learning experiences of students at the IRUC-PHC. It is important to highlight that the Personal Reflective Tool was developed on the basis of Bloom's taxonomy $[18,19]$ and on linkages with the learning objectives of the placement.

This tool helped demonstrate that students gained some knowledge of their own profession and other professions at the IRUC-PHC. This result is similar to findings by other researchers $[7,8,9,11]$. This finding reinforces D'Eon's conceptual framework [35] that students in the health professions might best be taught to become competent in the skills of their respective disciplines and in working together as healthcare teams by being exposed to cooperative-experiential approaches to engaging in those tasks.

In the current system, client care may be affected when various professionals struggle to maintain their own identities, culture, tradition, and influence. Illeris [36] suggests that to reduce tension among healthcare practionners, there must be a reconciliation between one's economic interests, moral values, social cooperation, and professional collaboration. Results indicate that students have developed some understanding and respect for other professions and that they recognize the added value of interprofessional care. They believe that this collaborative approach provides a better understanding of the client's situation and enhances intervention, this finding is similar to what has already been reported [8].

As illustrated above, the Personal Reflective Tool developed appears very useful for assessing interprofessional learning by identifying what students gained from this new experience and how an interprofessional placement helped them learn. Although it provides valuable information, analysis suggests that some changes are warranted. Thorough analysis of the questions revealed that certain question formulations may have influenced students' responses. For example, question 1 was phrased according to Bloom's [18,19] first level (i.e., comprehension level), which may have limited students' answers. Students essentially listed, defined, and identified new knowledge in relation to the interprofessional work and roles of others. However, considering that half of the students were in their final year of study, a higher level of cognitive learning might have been expected. Another example 
Assessing Interprofessional Clinical Learning

Guitard, Dubouloz, Savard, Metthé, \& Brasset-Latulippe

Journal of Research in Interprofessional Practice and Education

Vol. 1.3 December, 2010

\section{Journal of Research in Interprofessional Practice and Education}

noted for future change was question 2 . This question contained two very different concepts, i.e., the meaning and the importance of the determinants. A different approach is proposed to better capture the student's learning experience. We are asking students to describe a learning situation that enabled them to better understand the meaning of each of those determinants and adding a sub question that allows students to identify which determinant was most helpful in their interprofessional learning. This thorough analysis led to modifications of three questions in the tool (see Appendix 1).

\section{Limitations}

As no tool to specifically assess interprofessional learning was available, neither in English nor in French, one was developed. The Personal Reflective Tool is a written questionnaire to be completed at the end of an interprofessional placement. A guided interview may have provided opportunity for more precision and in-depth understanding of the student experience, but as this was not possible in the day to day operation at the IRUC-PHC, we opted for a written questionnaire. This form of assessment is also consistent with the other tools used to assess students' placements at the IRUC-PHC.

The analysis suggests that the wording of some questions led to specific types of responses and therefore need revision. This may have biased some of the results obtained; revisions to the Personal Reflective Tool have been made and the revised version is now being used at the IRUC-PHC.

Although this pilot project suggests that the Personal Reflective Tool is useful for assessing interprofessional learning, it needs to be trialed on a greater number of students.

Finally, with the single-group post-test-only design, we do not know whether the clinical placement condition had any effect on the participants, because we do not know what their response would have been if they were not exposed to the clinical placement. That is, we do not have a pre-test or a control group to make a comparison with. Another problem with this design is that we do not know if some confounding extraneous variable affected the participants' responses to the Personal Reflective Tool. In addition, although a single-group post-test-only design does control for temporal precedence, it does not control for history and maturation of the participants.

\section{Areas for future research}

Although it appears quite promising, the Personal Reflective Tool will have to undergo further development and testing to establish its psychometric properties. Further research is needed regarding interprofessional learning during an interprofessional clinical learning. More studies are needed to assess the most favourable length and timing of IPE placements to maximize the impact on future collaborative practice.

Another area for future research would be to study the specific contribution of IPE placements compared with various forms of IPE in the classroom. For example, 
Assessing Interprofessional Clinical Learning

Guitard, Dubouloz, Savard, Metthé, \& Brasset-Latulippe
Journal of Research in Interprofessional Practice and Education

as reported above, our data suggest that contrary to some beliefs, interprofessional care does not lead to the blurring of roles in the context of an IPE placement where students are supervised by a team that include a professional role-model from the same profession. We do not know if the results would have been the same if groups of students had done IPE case discussions in classrooms.

\section{Conclusion}

Assessing interprofessional clinical learning represents a challenge. No tool, in English or in French, specifically assessing interprofessional learning was identified. A tool was developed to explore the learning occurring during an interprofessional placement. A pilot project was conducted to explore the usefulness of the tool in assessing the knowledge developed through an interprofessional placement. The tool was trialed with 15 rehabilitation sciences students completing a rehabilitation placement at the Interprofessional Rehabilitation University Clinic in Primary Health Care.

Findings suggest that the Personal Reflective Tool developed was very useful in assessing IPE learning. This tool helped demonstrate that an interprofessional placement is an enriching experience at both the personal and professionnal levels. This tool suggests that through interprofessional placements, students gain a better understanding of their own profession and of other professions. According to the results, IPE is perceived as beneficial not only for students but for clients as well. Although the tool is most promising, it must be further studied to increase its usefulness in assessing interprofessional learning.

\section{Acknowledgements}

This research was supported by the Centre National de Formation en Sante and the Conseil académique en santé (programme de soutien à la recherche et à la formation interprofessionnelle [SRFI]).

\author{
Abbreviations \\ ADL Activities of daily leaving \\ CPCP Collaborative patient-centred practice model \\ HIV Human immunodeficiency virus \\ IPE Interprofessional education \\ RIPLS Readiness for Interprofessional Learning Scale \\ WHO World Health Organization
}

\section{References}

1. McPherson, K., Headrick, L., \& Moss, F. (2001). Working and learning together: Good quality care depends on it, but how can we achieve it? Quality in Health Care, 10(S2), 46-53.

Journal of Research in Interprofessional Practice and Education

Vol. 1.3

December, 2010
2. Heatth-Canada.-(2004).-Interprofessionalectucation for cotlaborative-patient=centred practice. URL:

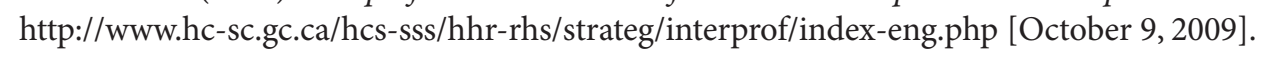

3. Barker, K., Bosco, C., \& Oadasan, I. (2005). Factors in implementing interprofessional education and collaborative practice initiatives: Findings from key informant interviews. Journal of Interprofessional Care, 19(S1), 166-176. 
243

Assessing Interprofessional Clinical Learning

Guitard, Dubouloz, Savard, Metthé, \& Brasset-Latulippe

Journal of Research in Interprofessional Practice and Education

Vol. 1.3

December, 2010
4. Reeves, S., \& Lewin, S. (2004). Interprofessional collaboration in the hospital: Strategies and meanings. Journal of Health Services \& Research Policy, 9(4), 218-225.

5. Barr, H. (2000). New NHS, new collaboration, new agenda for education. Journal of Interprofessional Care, 14(1), 81-86.

6. World Health Organization. (1988). Learning together to work together for health. Report of a WHO study group on multiprofessional education of health personnel: The team approach. (Technical Report Series No. 769). Geneva: World Health Organization.

7. Solomon, P., \& Jung, B. (2006). An interprofessional role-emerging placement in HIV rehabilitation. International Journal of Therapy and Rehabilitation, 13(2), 59-65.

8. Copley, J.A., Allison, H.D., Hill, A.E., Moran, M.C., Tait, J.A., \& Day, T. (2007). Making interprofessional education real: A university clinic model. Australian Health Review, 31(3), 351-357.

9. Lidskog, M., Löfmark, A., \& Ahlström, G. (2007). Interprofessional education on a training ward for older people: Students' conceptions of nurses, occupational therapists and social workers. Journal of Interprofessional Care 21(4), 387-399.

10. Anderson, E., Manek, N., \& Davidson, A. (2006). Evaluation of a model for maximizing interprofessional education in an acute hospital. Journal of Interprofessional Care, 20(2), 182-194.

11. Kapelus, G., Karim, R., Pimentao, B., Ferrera, G., \& Ross, C. (2009). Interprofessional health promotion field placement: Applied learning through the collaborative practice of health promotion. Journal of Interprofessional Care, 23(4), 410-413.

12. Fougeyrollas, P., Cloutier, R., Bergeron, H., Côté, J., \& St-Michel, G. (1998). Classification québécoise: Processus de production du handicap. Québec: RIPPH/CCIDIH.

13. D’Amour, D., Ferrada-Videla, M., San Martín-Rodríguez, L., \& Beaulieu, M.D. (2005). Interprofessionality as the field of interprofessional practice and interprofessional education: An emerging concept. Journal of Interprofessional Care, 19(S1), 8-20.

14. D’Amour, D., Ferrada-Videla, M., San Martín-Rodríguez, L., \& Beaulieu, M.D. (2005). The conceptual basis for interprofessional collaboration: Core concepts and theoretical frameworks. Journal of Interprofessional Care, 19(S1), 116-131.

15. Dubouloz, C-J., Savard, J., Burnett, D., \& Guitard, P. (2010). An interprofessional university clinic in primary health care in rehabilitation: A collaborative learning model for physical therapy students in a clinical placement. Journal of Physical Therapy Education, 24(1), 19-24.

16. Mezirow J. (2000). Learning as transformation: Critical perspectives on a theory in progress. SanFrancisco: Jossey-Bass.

17. Kolb D.A. (1984). Experiential learning: Experience as the source of learning and development. Englewood Cliffs, NJ: Prentice-Hall.

18. Bloom, B.S. (1956). Taxonomy of educational objectives, Handbook I: The cognitive domain. London: Longman.

19. Bloom, B.S. (1969). Taxonomie des objectifs pédagogiques, Domaine cognitif. Montréal: Les Presses de l'Université de Québec.

20. San Martin-Rodriguez, L., Beaulieu, M.D., D’Amour, D., \& Ferrada-Videla, M. (2005). The determinants of successful collaboration: A review of theoretical and empirical studies. Journal of Interprofessional Care, 19(S1), 132-147.

21. Krathwohl, D.R., Bloom, B.S., \& Masia, B.B. (1975). Taxonomie des objectifs pédagogiques: Tome 2: domaine affectif. Montréal: Education Nouvelle.

22. Mattick, K., \& Bligh, J. (2005). An e-resource to coordinate research activity with the Readiness for Interprofessional Learning Scale (RIPLS). Journal of Interprofessional Care, 19(6), 604-613.

23. Parsell, G., \& Bligh, J. (1999). The development of a questionnaire to assess the readiness for health care students for interprofessional learning (RIPLS). Medical Education, 33, 95-100.

24. Slack, M.K., Coyle, R.A., \& Draugalis, J.R. (2001). An evaluation of instruments used to assess the impact of interdisciplinary training. Issues in Interdisciplinary Care, 3(1), 59-67.

25. Carpenter, J. (1995). Doctors and nurses: Stereotypes and stereotype change in interprofessional education. Journal of Interprofessional Care, 9(2), 151-161.

26. Lindqvist, S., Duncan, A., Shepstone, L., Watts, F., \& Pearce, S. (2005). Development of the 'Attitudes to Health Professionals Questionnaire' (AHPQ): A measure to assess interprofessional attitudes. Journal of Interprofessional Care, 19(3), 269-79. 


\section{JRIPE}

244

Assessing Interprofessional Clinical Learning

Guitard, Dubouloz, Savard, Metthé, \& Brasset-Latulippe

\section{Journal of Research in Interprofessional Practice and Education}

27. Luecht, R.M., Madsen, M.K., Taugher, M.P., \& Petterson, B.J. (1990). Assessing professional perceptions: Design and validation of an interdisciplinary education perception scale. Journal of Allied Health, Spring, 181-191.

28. Kettenbach, G. (2009). A comparison of attitudes and perceptions towards team work and IPE of students without IPE at the beginning and the end of their professional health care curricula. Paper presented at Collaborating Across Borders II Conference, May 20-22, Halifax, Nova Scotia, Canada.

29. Howell, D., Lyons, K., \& Giordano, C. (2009). Evaluating interprofessional experience: A mixed view from two universities. Paper presented at Collaborating Across Borders II Conference, May 22, Halifax, Nova Scotia, Canada.

30. Haig, A.J., \& LeBreck, D. (2000). Measurement of change in rehabilitation team dynamics with the team assessment profile (TAP). International Journal of Rehabilitation and Health, 5(2) 71-83.

31. D’Amour, D., Goulet, L., Labadie, J.F., San Martín-Rodriguez, L., \& Pineault, R. (2008). A model and typology of collaboration between professionals in healthcare organizations. BMC Health Services Research, 8, 188.

32. Mackay, S. (2004). The role perception questionnaire (RPQ): A tool for assessing undergraduate students' perceptions of the role of other professions. Journal of Interprofessional Care, 18(3), 289-302.

33. Caelli, K., Ray, L., \& Mill, J. (2003). 'Clear as mud': Toward greater clarityy in generic-qualitative; Iresearch.- Internationat Journat- of Qualitative Methods, 2(2). URL: 'Ltttp://www.ualberta.cal' 1/ iiqu_backissues/pdf/caellietal.pdf !'March 23, 2010].

34. Merriam, S.B. (1998). Qualitative research and case study applications in education. San Francisco: Jossey-Bass.

35. D’Eon, M. (2005). A blueprint for interprofessional learning. Journal of Interprofessional Care, 19(S1), 49-59.

36. Illeris, K. (2002). The three dimensions of learning: Contemporary learning theory in the tension field between the cognitive, the emotional and the social. Roskilde, Denmark: Roskilde University Press. 
Appendix 1

Assessing Interprofessional Clinical Learning

Guitard, Dubouloz, Savard, Metthé, \& Brasset-Latulippe
Journal of Research in Interprofessional Practice and Education

Vol. 1.3

December, 2010

\section{Réflexion personnelle sur l'apprentissage interprofessionnel lors d'un stage en réadaptation}

(Personal reflection on interprofessional learning during a clinical placement in rehabilitation)

\begin{tabular}{|l|l|}
\hline \multicolumn{1}{|c|}{ Version 1 } & \multicolumn{1}{c|}{ Version 2 } \\
\hline $\begin{array}{l}\text { 1. Relater une expérience précise, un moment } \\
\text { révélateur, qui vous a permis d'améliorer votre } \\
\text { compréhension du travail interprofessionnel et du rôle } \\
\text { d'un autre professionnel (un rôle que vous ne } \\
\text { connaissiez pas avant ce stage). }\end{array}$ & $\begin{array}{l}\text { 1. Qu'avez-vous appris sur la pratique d'un autre } \\
\text { professionnel que vous connaissiez moins? } \\
\text { Comment pourriez-vous appliquer ces apprentissages } \\
\text { dans votre pratique? }\end{array}$
\end{tabular}

Describe a single experience, an enlightening moment that allowed you to improve your comprehension of interprofessional work and the role of another professional (a role that you didn't know before the placement).

What did you learn about the practice of another professional with which you were less familiar? How could you apply that knowledge in your own work?
2. Relater une expérience précise, un moment révélateur, qui vous a permis de mieux saisir le sens ou l'importance des déterminants interactionnels de l'interprofessionalisme : désir de collaboration; communication; confiance; respect.

Describe a single experience, an enlightening moment that allowed you to better understand the meaning or the importance of interprofessionalism's interactional determinants: willingness to collaborate, trust, communication, and respect.
2. A) Quatre déterminants interactionnels ont été identifiés: désir de collaborer, confiance, communication et respect. Décrivez une situation qui vous a permis de mieux saisir le sens de chacun de ces déterminants:

Four interactional determinants were identified: willingness to collaborate, trust, communication, and respect. Describe a situation that allowed you to better understand the meaning of each of those determinants.

2. B) Le ou lesquels de ces déterminants vous a permis de progresser dans votre cheminement interprofessionnel?

Which one(s) of those determinants helped you in your interprofessional learning progress?

3. Relater une expérience précise, un moment révélateur, qui vous a permis d'appliquer le travail interprofessionnel auprès d'un client. Préciser comment le fait d'avoir offert une intervention interprofessionnelle (plutôt que des interventions isolées de 2 professionnels) peut avoir fait une différence pour le client.

Describe a single experience, an enlightening moment that allowed you to apply interprofessional work with a client. Specify how the interprofessional intervention (instead of isolated interventions from 2 different professionals) could have made a difference for the client.
3. Décrivez une situation d'évaluation ou d'intervention interprofessionnelle à laquelle vous avez participé. Comment cette collaboration interprofessionnelle, en comparaison à des interventions disciplinaires, a pu faire une différence pour :

a) Le client? b) Létudiant?

c) La clinicienne-éducatrice?

Describe a situation of interprofessional assessment or intervention in which you were involved. How did this interprofessional collaboration, compared to disciplinary interventions, made a difference for:

a) The client? b) The student?

c) The clinician-educator ? 


\section{JRIPE}

246

Assessing

Interprofessional

Clinical Learning

Guitard, Dubouloz, Savard, Metthé, \& Brasset-Latulippe

Journal of Research in Interprofessional Practice and Education

\begin{abstract}
4. Qu'est-ce qui vous a le plus surpris dans ce stage?
a)Par rapport à nimporte quelle situation du stage

b) Par rapport à une autre profession

What surprised you most about this placement?

a) Regarding any given situation

b) Regarding another profession?
\end{abstract}

5. Pouvez-vous décrire une situation qui vous a fait penser autrement et la réflexion que cette situation vous a fait faire?

Can you describe a situation that made you think differently and the reflection you had following that situation?

6. Pouvez-vous décrire une situation qui vous a fait modifier vos façons habituelles de travailler et décrire ce changement?

Can you describe a situation that made you change the way you work and describe that change?
4. No change

5. No change

6. No change 